\title{
Trabajo Social Socio Juríico en Chile: génesis, desarrollo histórico y desafíos disciplinares*
}

\author{
Sociolegal social work in Chile: \\ genesis, historical development and disciplinary challenges
}

Sara Salum-Alvarado

Asistente Social, Criminóloga, PH Master International Social Work, Doctora en Estudios Americanos. Académica e investigadora, Escuela de Trabajo Social, Universidad de Valparaiso-Chile. sara.salum@uv.cl

\section{Elena Salum-Alvarado}

Asistente Social, Magíster en Gestión y Políticas Públicas, Doctora en Estudios Americanos. Académica e investigadora Escuela Trabajo Social Universidad de Valparaíso. elena.salum@uv.cl

RESUMEN: Este artículo desarrolla la génesis del Trabajo Social Socio Jurídico bajo la influencia del higienismo y del modelo jurídico de la época en que se crea la profesión en Chile. Aborda su desarrollo disciplinar desde 1928 y el cambio de paradigma a partir de la Convención de los Derechos del Niño en 1990, identificando algunos hitos que han marcado los desafíos que el Trabajo Social Socio Jurídico ha enfrentado en los 90 años de existencia del Trabajo Social en Chile.

Palabras clave: Trabajo Social. Génesis. Modelos. Desafíos Disciplinares.
ABSTRACT: This article develops the genesis of socio-legal social work under the influence of hygienism and legal model of the time when the profession in Chile is created. Discusses its development discipline since 1928 and the paradigm shift from the Convention on the Rights of the Child in 1990, identifying some milestones that have marked the challenges that social work partner law has faced in 90 years of the Social Work Chile.

Keywords: Sociolegal Social Work. Genesis. Models. Disciplinary Challenges.

* Articulo financiado por Conveanio de Desempeño Institucional de las Humanodades, Artes y Ciencias Sociales UVA 0901 y Escuela Trabajo Social Universidad de Valparaíso. Chile. 
A Elena, mi madre, que iluminó con su amor, sabiduría, inteligencia, ternura, complicidad y belleza mi vida y a quien le debo ser quien soy. Fue un ángel, bella, etérea, dulce.

Invierno 2016.

\section{La influencia histórica del higienismo como génesis del Trabajo Social Socio Jurídico chileno}

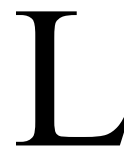

a primera escuela de Trabajo Social que se fundó en Chile fue la Escuela de Servicio Social Dr. Alejandro del Río en el año 1925, bajo el influjo del higienismo, corriente que tanto en Chile como en Latinoamérica, propugnaba la necesidad de la intervención del Estado frente a las consecuencias del industrialismo y la urbanización. En este contexto, el Estado intenta mediar la "Cuestión Social" no como un deber caritativo sino bajo un enfoque técnico. La creación de esta Escuela surge como resultado de la visita del Dr. Alejandro del Río a Europa - específicamente a Bélgica - donde conoce a las visitadoras sociales y el modelo de intervención de problemáticas sociales implementado en ese país, elemento que contribuyó a cimentar el Trabajo Social en Chile.

El higienismo y el servicio social a comienzos de la década de 1920 aúnan sus esfuerzos y cristalizan la preocupación de las autoridades de la época, respecto de los problemas de la salud pública, los que comienzan a ser vistos como una consecuencia social de las condiciones económicas del país.

En este contexto, Lucero (1995) plantea: "Las intervenciones higienistas buscaban no sólo asegurar la reproducción física de la población (aumentando la esperanza de vida), sino también la reproducción social y cultural, mediante estrategias de moralización y disciplinamiento" (p. 44).

De igual forma, Zárate (1999) señala:

El higienismo convirtió la crianza de los niños en una preocupación en las primeras décadas del siglo, involucrando por vez primera al Estado en la relación entre la madre y su hijo y en la elaboración de políticas públicas que 
permitieran el control de las tasas de morbilidad y mortalidad infantil así como de los abortos e infanticidios. (p. 207)

En relación a los inicios de la profesión Quiroz (1998) afirma:

La profesión nació con un carácter feminista y de orientación predominantemente paramédica, recibiendo en sus inicios influencias Europeas (alemana, belga y francesa). En este caso fue esencialmente belga y la concepción fue de corte benéfico asistencial, siendo su área de acción la Salud, dado que la Junta Nacional de Beneficencia tenía como prioridad fundamental la Organización y Administración de Hospitales para indigentes y asegurados. De ahí que en su primera etapa, su enseñanza tendió a preparar personal para que actuara en el campo médico-social, en organismos públicos de asistencia y Seguridad Social, atendiendo al enfermo y su grupo familiar, centrando su atención en el tratamiento de problemas sociales que afectaban la recuperación del paciente y además aportar datos del medio ambiente al médico, para contribuir al diagnóstico y tratamiento. (p. 17)

El Trabajo Social se institucionaliza como disciplina y profesión a partir del momento en que el Estado moderno asume e implementa una respuesta organizada frente a la cuestión social, ubicándose en un rol mediador entre los llamados problemas sociales y los recursos del Estado, rol que estuvo impregnado en sus inicios por la influencia de prácticas caritativas de inspiración religiosa, propias del período pre industrial, adoptando posteriormente a partir de su profesionalización, una mirada científica de marcada influencia positivista, que deriva en una intervención pragmática a partir del estudio, categorización y clasificación de los problemas sociales (Leblanc, 2009).

\section{La influencia del modelo de justicia en la formación del Trabajo Social Socio Jurídico en Chile}

La ligazón del Trabajo Social al derecho y la configuración de sus roles en el campo de la administración de justicia tiene una larga historia, no solo en Latinoamérica sino también en Europa y Estados Unidos. 
Siguiendo a Ponce de León (2014), el Trabajo Social Socio Jurídico o forense cuenta con un desarrollo significativo en la vertiente anglosajona de éste, cuyas intervenciones estuvieron presentes desde los orígenes del Trabajo Social como disciplina académica. En los inicios del siglo XX se fundó una práctica que integraba lo social y lo jurídico como un modo de abordar la conflictividad social de principios de siglo. Entre los trabajos pioneros de esta disciplina se encuentran los trabajos de Mary Richmond y su aporte en la creación de los tribunales de menores; Jane Adams en la defensa de los derechos civiles, sociales y políticos de niños, niñas y mujeres; Dorothea Linde Dix en el incipiente Trabajo Social penitenciario y finalmente los trabajos de Jessie Taft y Virginia Robinson en temáticas como la adopción.

En Chile, el Trabajo Social Socio Jurídico es de antigua data y funda sus orígenes formales ya a mediados de la década de 1920, con una ligazón al derecho de familia, a la administración del sistema de justicia de menores y familia de la época y de las incipientes leyes que pretendían sentar las bases de un sistema de protección de menores.

De esta manera, es difícil aislar el Trabajo Social Socio Jurídico de la actividad del tribunal de menores y familia de la época. No obstante, esta misma ligazón es la que ha permitido configurar la evolución de la intervención de la profesión en este campo, dados los cambios que ha experimentado la legislación del derecho de familia y menores a lo largo del tiempo marcando una trayectoria plenamente identificable.

La influencia del modelo de justicia de la época en Chile instaló al asistente social como un como auxiliar de justicia y como un dispositivo de control social. Mitjavila, Krmpotic y De Martino (2008) advierten como el campo jurídico constriñe las formas de abordaje de problemas a Trabajo Social:

El campo socio jurídico, sus prácticas profesionales y discursos son conformados a partir de la norma legal, es decir, a partir del poder judicial, de los agentes profesionales del derecho y del saber jurídico. El ejercicio profesional del Trabajo Social en este campo se encuentra predominantemente demarcado, en términos de problemas, espacios ocupados y referenciales teóricos y 
fácticos, por el habitus del campo jurídico... Este define las formas de abordaje profesional de esos mismos problemas por parte del Trabajo Social (p. 156).

La trayectoria, la modalidad de trabajo y las técnicas se han adecuado al funcionamiento de las instituciones de justicia y desde allí se han definido un usuario y un problema justiciable sobre el que los profesionales han actuado. El rol de inspector, la vigilancia, las averiguaciones y el control han dibujado unos contornos profesionales que remiten a aquella expresión “ojos y oídos del juez" lo que con el tiempo será planteada en términos de diagnóstico social aunque junto a una cuestionada sacralización instrumental (Krmpotic, 2013).

Quinteros (2014) afirma:

Concebido como una especialidad que focaliza en la interfase entre el sistema legal y el sistema de servicios sociales, el Trabajo Social forense encuentra sentido, toda vez que una dimensión legal se encuentra afectada o en litigio. En ese sentido, la práctica forense no debe limitarse a los procesos judicializados, puesto que la resolución de conflictos se realiza tanto dentro como fuera de la administración de justicia, antes y después de que intervenga y dictamine. Por su parte, la demanda social y la agenda pública exigen hoy contar con profesionales que comprendan la función social del derecho, se encuentren capacitados en el arbitraje, el diagnóstico social fundado (eventualmente, con finalidad pericial en un proceso judicial), y en una intervención tanto restitutiva -ante daños- como promotora de derechos. Para el Trabajo Social el desafío no es ajeno a su propia historia en la medida en que se trata de una profesión que siempre ha intervenido en los vínculos problemáticos entre las personas y sus contextos, fundada en los derechos humanos y la justicia social. (pp. 30-31)

Así, desde sus inicios, el desarrollo de la profesión estuvo ligado al control social de las familias pobres y marginales estableciendo un modelo a seguir centrado en las normas sociales y modelos patriarcales de familia fuertemente arraigados en la época, lo que lleva a configurar al Trabajo Social en el sector justicia como un auxiliar al juez en materias que no eran de su experticia. 
En contextos no-clínicos, el diagnóstico social centrado en la familia fue un distintivo en el área jurídica, en donde las técnicas de la visita domiciliaria, la observación, las entrevistas (individual y familiar), la coordinación y la derivación fortalecieron el rol del trabajador social de la época en el tribunal de menores y familia moldeando el perfil de éste (Quinteros, 2014).

En sus inicios fueron mayoritariamente funcionarios judiciales de sexo femenino. Esto da cuenta de que la profesión al igual que en otros países de Latinoamérica se encontraba feminizada y su misión era colaborar con el juez de menores e informarle acerca de los aspectos sociales, económicos, ambientales, educacionales y demás que le solicitase el juez, que rodeasen a los menores o a los hechos que provocaron o causaron una conducta irregular en ellos. Cabe mencionar de igual forma, que durante este período, los jueces de menores y familia fueron preponderantemente de sexo femenino, por lo que se gestaba una predominancia femenina en este sistema judicial, con un marcado énfasis en la familia tradicional.

La presencia del Trabajo Social en el sistema de administración de justicia, específicamente en los tribunales de menores y su marcada feminización en los inicios de la profesión permitió acumular una experticia sobre temas sociales y familiares, económicos, de vivienda, de peligrosidad, que estableció un escenario profesional privilegiado con límites claramente establecidos hacia otras profesiones que intentaban disputarse el ámbito social y la experticia frente al sistema judicial.

De acuerdo a la cultura jurídica impuesta en estos tribunales, la entrevista con el trabajador(a) social, la visita domiciliaria realizada por éste(a) y la opinión profesional que emitían, tenían un peso preponderante en la sentencia que la jueza de menores emitía.

Con el paso del tiempo, se va consolidando el poder hegemónico del trabajador(a) social al interior del tribunal de menores, estableciendo una tensión entre la realidad, los cambios sociales y las decisiones judiciales que se tomaban, las cuales en gran parte se fundaban en su opinión, razón por la cual muchas veces fueron temidas y odiadas. 
Fue así como toma fuerza la presencia del trabajador social como auxiliar de justicia, el que desde la legislación de la época y hasta la actualidad se erige como el único profesional del área social capacitado y reconocido legalmente para emitir opiniones respecto de situaciones sociales, económicas y familiares a través del informe social y de la firma profesional y del peritaje social.

\section{El Trabajo Social Socio Juríico o forense y el cambio de paradigma a partir de la Convención de los Derechos del Niño}

La Forensic Social Work Organization (FSWO 2012) define el Trabajo Social Socio Jurídico o forense como la aplicación de las cuestiones y problemas del Trabajo Social en relación con el derecho y los sistemas de administración de justicia, ligando estrechamente la especificidad profesional a los sistemas de administración de justicia.

Ponce de León (2014) reconoce el Trabajo Social forense como una subespecialidad que aplica un enfoque integral para la práctica del Trabajo Social con poblaciones diversas afectadas por problemas legales, tanto civiles como penales. Para el autor, el término forense subraya la fusión de la justicia social y los principios de los derechos humanos.

En este contexto, ingresa a la disciplina la perspectiva socio-jurídica, como una nueva perspectiva fundante de la práctica profesional dentro o fuera de los sistemas de administración de la justicia en el Estado moderno, caracterizado en principio por la burocratización, los vertiginosos cambios normativos y lo que podríamos llamar nuevos paradigmas jurídicos.

La perspectiva socio jurídica se entiende como un diálogo entre las esferas de la intervención social del Trabajo Social basada en las perspectivas teóricas provenientes de la teoría social y de la teoría jurídica, donde la esfera ética como eje central de las intervenciones del Trabajo Social cobra protagonismo (Ponce de León, 2014; Aguayo, 2007).

A partir de 1990 Chile ratifica la Convención de Derechos del Niño, surgiendo la doctrina de la protección integral. Este hecho marcó un cambio 
en el rol del Estado frente a la infancia y la adolescencia, pasando de un Estado tutelar a un Estado Garante de derechos y un cambio sustantivo en la política pública.

El Trabajo Social Socio Jurídico o forense se va abriendo hacia nuevos escenarios, siempre determinados por la norma jurídica. Con la llegada del nuevo milenio, surgen para el Trabajo Social Socio Jurídico dos hitos que cambiaron el rol tradicional e histórico del trabajador social: la reforma procesal penal y los tribunales de familia.

\section{Primer hito: la Reforma Procesal Penal y el peritaje social}

En Chile, entre los años 2000 y 2005, se instaura en forma progresiva un nuevo proceso penal, basado en la oralidad, dejando atrás el antiguo sistema penal escriturado, de carácter inquisitivo y decimonónico.

A partir del nuevo proceso penal en Chile, surge el rol del peritaje social en el campo penal. Si bien la realización de peritaje en Chile no es nueva, pues desde sus inicios el profesional actúo como experto que informaba al tribunal de materias de su competencia, pero no es sino hasta este periodo en el que aparece en Chile la necesidad de un peritaje regulado por el proceso penal, delineándose la pericia social forense.

En la pericia social forense, el perito trabajador social debe dar cumplimiento a las demandas de un proceso penal nuevo, oral, desconocido hasta la fecha en el país. Así el perito aparece como un experto en materias sociales, económicas y familiares, pero por primera vez, su dictamen puede ser cuestionado por las partes en conflicto. Su actuar deja de ser una opinión profesional que sugiere al juez ciertas determinaciones o acciones a seguir y pasa a ser un dictamen pericial, el cual debe ser defendido en la audiencia oral.

Este nuevo escenario tensiona el actuar de los trabajadores sociales, pues en la audiencia oral el proceso penal le exige al profesional fundamentaciones teóricas y metodológicas concretas, las que se deben concordar con estudios científicos y metodologías de probada efectividad. Si bien los profesionales siempre han estado en posesión de conocimientos científicos 
y metodológicos que fundan nuestro actuar, se produjo por primera vez una brecha entre lo jurídico y lo social. Esto, porque los profesionales del derecho muchas veces desconocen el lenguaje, las metodologías y las técnicas del Trabajo Social, lo que da cuenta de que pese a muchas décadas de convivencia entre el derecho y el Trabajo Social, nunca existió un real diálogo o vasos comunicantes entre ambas disciplinas.

Esto no solo ha marcado el desenvolvimiento profesional dentro de los tribunales - ya sean civiles o penales - sino que también ha marcado el desenvolvimiento en las tareas de los profesionales que si bien no se encuentran dentro del sistema judicial, si deben vincularse con problemáticas relacionadas con una decisión judicial.

Pese a los avances a nivel legislativo, la situación de la infancia y la adolescencia en Chile sigue siendo crítica. Si bien se han promulgado leyes que han instaurado un nuevo paradigma bajo un enfoque de derechos, la realidad da cuenta de grandes falencias en el real cumplimiento del resguardo y respeto de los derechos de la infancia. Entre éstas podemos señalar que Chile es uno de los pocos países en Latinoamérica que no cuenta con una Ley de Protección Integral de la Infancia y la Adolescencia, tampoco cuenta con un Código de Familia ni con la institucionalidad de la Defensoría del Niño.

Este complejo escenario, genera que el Trabajo Social deba adscribirse a distintas legislaciones orientadas a la protección de la infancia para desarrollar intervención social. La transformación del campo laboral del profesional trabajador social, trajo como consecuencia que éstos deban realizar su actuar profesional bajo el reconocimiento de los derechos humanos y en especial, los derechos de los niños.

Segundo hito: la transformación del sistema judicial de familia en Chile: los tribunales de familia y el surgimiento de los consejos técnicos

Con la llegada del nuevo milenio y debido a la necesidad de establecer nuevos procesos judiciales basados en la oralidad, se implementa la Reforma al sistema judicial de menores y familia, lo que llevó a la creación de los 
Tribunales de Familia. Esto provocó la pérdida de la exclusividad y hegemonía que durante décadas ostentó la profesión, siendo reemplazada por un nuevo operador judicial denominado Consejero Técnico.

El año 2004 se promulga la ley $N^{\circ} 19.968$ que crea los Tribunales de Familia y Menores, la que estableció un drástico cambio en el procedimiento de familia, pasando de un sistema escriturado e inquisitivo a un sistema procesal oral, desconcentrado y desformalizado con influencia de la tecnología y con la presencia de nuevos operadores judiciales. En el artículo $\mathrm{N}^{\mathrm{o}} 2$, esta ley establece la creación de los Consejos Técnicos y en su artículo $N^{\circ} 5$, establece sus funciones, señalando que corresponde a los miembros de este Consejo asesorar, individual o colectivamente, a los jueces en el análisis y mejor comprensión de los asuntos sometidos a su conocimiento, en el ámbito de su especialidad.

También establece que entre sus atribuciones se cuentan asistir a las audiencias de juicio a que sean citados con el objetivo de emitir las opiniones técnicas que le sean solicitadas; asesorar al juez para la adecuada comparecencia y declaración del niño, niña o adolescente, y evaluar, a requerimiento del juez, la pertinencia de derivar a mediación o aconsejar la conciliación entre las partes y sugerir los términos en que esta última pudiere llevarse a cabo; asesorar al juez, a requerimiento de éste, en la evaluación del riesgo que establece la Ley de Violencia Intrafamiliar (Ley No 20.066 de 2005), y finalmente, asesorar al juez en todas las materias relacionadas con su especialidad.

De igual forma, la Ley de Tribunales de Familia establece que los consejos técnicos son instancias interdisciplinarias integradas por profesionales especializados en familia e infancia con carácter de auxiliares de justicia.

Este hecho, marca un hito importante en el Trabajo Social jurídico o forense, por cuanto desaparece la presencia del trabajador social como un funcionario perteneciente a la judicatura de familia, surgiendo una nueva instancia colegiada de carácter interdisciplinaria: el Consejo Técnico. En éste cualquier profesional de las ciencias sociales puede acceder al cargo de consejero técnico. Si bien en la práctica se ha dado que éste debe estar compuesto por al menos un psicólogo y un trabajador social, el rol histórico y el status que la profesión ostentó por 77 años, desaparecen. 
En este nuevo escenario, al consejero técnico le corresponde un rol asesor del juez, toda vez que los miembros de este consejo no tienen ninguna vinculación con la actividad probatoria en el proceso. Es decir, ya no produce informes sociales que incidan en la decisión del juez como en el antiguo sistema, toda vez que en este nuevo sistema el juez toma su decisión en base a la sana crítica. En este nuevo escenario, el consejero técnico puede emitir su opinión en las audiencias (audiencia preparatoria y audiencia de juicio) y también puede emitir su opinión fuera de las audiencias, recomendando procedimientos de mediación o conciliación. También tiene un rol de coordinador y articulador de la red social en materias de riesgo de vulneración de derechos en casos que involucren niños, niñas y adolescentes.

De esta manera, la ausencia del trabajador social en su rol tradicional y disciplinar es reemplazada por la figura del consejero técnico. Esto le exige un desdoblamiento para cumplir con los nuevos roles del consejero técnico y sus propios criterios de intervención. Esto es fundamental de entender, pues en este escenario, no existe la intervención social al interior del tribunal. Esta ha sido desplazada a la red social, recargando a los trabajadores sociales, especialmente del área de la salud, para suplir la ausencia de esta figura en el Tribunal.

Esto se refleja en el hecho de que el consejero técnico trabajador social puede solicitar evaluaciones de maltrato habitual y de riesgo inminente según lo establece la Ley de Violencia Intrafamiliar No 20.066 de 2005, así como también sugerir medidas cautelares en materia de protección y reparación de derechos vulnerados.

Por otra parte, en la práctica se han ido asumiendo nuevas funciones no descritas en la Ley de Tribunales de Familia. Entre éstas podemos señalar la obligatoriedad de realizar visitas a centros residenciales acompañando al juez de familia; la entrevista con la parte previa a la audiencia en búsqueda de acuerdos conciliatorios; el registro y actualización de los ingresos de niños, niñas y adolescentes a centros residenciales; registros de las visitas realizadas por el juez; confección de fichas y, finalmente, asesorías. Si bien estas funciones no están claramente descritas en la Ley de Tribunales de Familia, este mismo hecho ha generado una recarga de trabajo de tipo administrativo, generando un deterioro en la calidad de las funciones de los consejeros técnicos. 
Pareciera ser que este lento tránsito desde un enfoque antiguo tutelar a uno más novedoso garante de derechos ha generado una suerte de invisibilización de los roles y funciones que distinguen a un trabajador social. Esto ha sido en gran medida determinado por la precarización de los mercados laborales de la profesión. Hoy los trabajadores sociales deben insertarse en un mercado laboral regido por el modelo neoliberal que se funda en el principio de la subsidiariedad y en los actuales sistemas de licitación de programas de intervención en infancia y adolescencia.

Esto ha desmantelado el rol tradicional del trabajador social socio-jurídico, imponiéndole nuevas lógicas de trabajo. Si bien esto es algo que afecta a la profesión, también puede ser visto como una oportunidad de reinvención teórica y metodológica, dado que en Chile las páginas del Trabajo Social Socio Jurídico se encuentran aún escribiéndose, pese a que han pasado ya 25 años desde el retorno a la democracia.

\section{A modo de conclusión}

La historia del Trabajo Social Socio Jurídico en sus orígenes estuvo ligado fuertemente al modelo médico y la influencia del higienismo así como al modelo jurídico de la época y al sistema de administración de justicia. Ambas influencias, tanto la del modelo médico como la del antiguo sistema de justicia tuvieron como factor común el debilitamiento de los mecanismos formales e informales de socialización y control social de la época, frente a un creciente aumento de la conflictividad social, lo que permitió el surgimiento de las antiguas visitadoras sociales, las que con el tiempo se transformaron, tecnificaron y se convirtieron en asistentes sociales, para finalmente hacia la llegada del segundo milenio denominarse trabajadoras(es) sociales.

Si bien, las décadas de desarrollo del Trabajo Social al interior del sistema judicial generaron una identidad y una experticia propia del gremio, ésta no logró cristalizarse ni instalarse en el nuevo sistema judicial de familia. Sigue primando en los operadores judiciales - consejeros técnicos de profesión trabajadores sociales — la lógica del antiguo sistema tutelar. Muchas 
veces los consejeros técnicos actúan como trabajadores sociales, olvidando que la legislación les otorga un rol distinto, privándoles de la posibilidad de intervenir las problemáticas y asignándoles nuevos roles como el de asesor del juez, el peritaje social y el de articulador de redes.

Por último, la llegada de la Convención de los Derechos del Niño, ha marcado un nuevo escenario al Trabajo Social Socio Jurídico, debiendo internalizar el Trabajo Social un enfoque de derechos humanos, en el que el Trabajo Social Socio Jurídico debe transformarse ahora en un profesional garante de los derechos humanos.

El Trabajo Social Socio Jurídico en la actualidad se presenta como una especialidad del Trabajo Social en permanente evolución, en un esfuerzo por responder a la necesidad de instaurar el respeto a los derechos humanos y el empoderamiento de la ciudadanía, como nuevos escenarios en los cuales éste debe desenvolverse.

Si bien ha logrado consolidar un campo de acción profesional específico, surge una tensión en el hecho de que el Trabajo Social Socio Jurídico chileno no ha logrado generar una metodología específica de acción. Los distintos procesos legales han generado nuevos operadores judiciales que le exigen al trabajador(a) social situarse en nuevos escenarios en el marco de los derechos humanos (peritaje y consejeros técnicos), que operan desde una perspectiva de asesores especializados, pero carentes de peso específico a nivel de la toma de decisión judicial del juez.

Trabajo Social en esta área se encuentra aún en un proceso de maduración y de búsqueda de metodologías propias que emanen de la propia práctica y no solo de los lineamientos establecidos por las políticas públicas. Si bien este hecho puede ser visto como un elemento que profundice en el campo de la investigación y la creación de nuevos modelos de intervención propios del Trabajo Social, éste se debate entre los elementos teóricos y metodológicos provenientes de otras disciplinas sociales, en especial de las ciencias del comportamiento.

Recebido em 19/8/2016 - Aprovado em 17/9/2017 


\section{Referencias bibliográficas}

AGUAYO, C. et al. (2007) Ética y Trabajo Social en las voces de sus actores: un estudio desde la práctica profesional. Santiago de Chile: Colegio de Asistentes Sociales.

KMPROVIC, C. (2013) El Trabajo Social forense como campo de actuación de lo social. Trabajo Social Global. Revista de Investigaciones en Intervención Social, 3 (4), 37-54. Disponible en: <http://revistaseug.ugr.es/index.php/tsg/article/view/957>. Acceso en 23/06/2016.

LEBLANC C. (2009) "Los desafíos de la formación profesional en la cuestión social contemporánea”. XIX Seminario Latinoamericano de Escuelas de Trabajo Social: El Trabajo Social en la Coyuntura Latinoamericana, Ecuador.

LUCERO, M. (1995) Modelos Políticos y Perfil del Trabajador Social. Un Análisis prospectivo hasta la actualidad. Universidad Nacional de San Juan Facultad de Ciencias Sociales Departamento de Trabajo Social (GEITS) San Juan. Disponible en: <http:// www.ts.ucr.ac.cr/binarios/pela/pl-000006.pdf>. Acceso en 10/06/2016.

MITJAVILA, M.; KRMPOTIC, C.; DE MARTINO, M. (2008) El Trabajo Social en el campo socio-judicial: construcción socio-histórica, modalidades, problemas y desafíos recientes en Argentina, Brasil y Uruguay. Revista Colombiana de Trabajo Social, N²1. Colombia.

PONCE DE LEÓN, A. Recorrido conceptual y anclaje socio histórico del Trabajo Social forense o Trabajo Social en perspectiva socio-jurídica. XXVII Congreso Nacional de Trabajo Social. De 11 a 13 de sept. de 2014. Disponible en: <https://issuu.com/faapss/ docs/ponce_de_leon>.Acceso en 20/06/2016.

QUINTEROS, A. Revista Facultad de Trabajo Social, vol. 30, № 30, pp. 25-40, ene.dic./2014, ISSN: 0121-1722, Medellín, Colombia, 2014. Disponible en: <file://C:/Users/ Sara\%20Salum/Downloads/3319-6683-1-SM.pdf>. Acceso en 23/06/2016.

QUIROZ, M. (1998) Antología del Trabajo Social Chileno. Concepción, Chile: Universidad de Concepción.

REPÚBLICA DE CHILE, Ley N 19.968 del 3 de agosto de 2004.

REPÚBLICA DE CHILE, Ley N ${ }^{\circ} 20.066$ del 7 de octubre de 2005.

ZÁRATE, S. (1999) Proteger a las madres: origen de un debate público 1870-1920. Nomadías 1, Santiago: Universidad de Chile. Disponible en: $<\mathrm{http}: / /$ politicaspublicas. uc.cl/wp-content/uploads/2015/02/serie-no-61-la-mujer-ayer-y-hoy-un-recorrido-deincorporacion-social-y-politica.pdf $>$. Acceso en 10/06/2016.

Este es un artículo de acceso abierto distribuido bajo los términos de la Creative Commons Attribution License. 